\title{
Study on effect of water-fertilizer coupling on water consumption and growth of young grape
}

\author{
Ping. Gong ${ }^{1, \mathrm{a}}$, Hongguang $\mathrm{Liu}^{1, \mathrm{~b}}$ and Xinlin $\mathrm{He}^{1, \mathrm{c}}$ \\ ${ }^{1}$ College of Water Conservancy \& Architectural Engineering Shihezi University, Shihezi \\ a610806842@qq.com, blhg123@shzu.edu.cn, chexinlin2013@126.com
}

Keywords: water and fertilizer; grape; water consumption; growth

Abstract. Soil moisture and nutrients are different under different water and fertilizer conditions, which will affect crop growth and yield. In this study, water consumption, growth index, yield under different treatments were measured and analyzed in order to investigate the effect of coupling of water and fertilizer on grape growth and water consumption and select the optimal ratio of water and fertilizer. The results show that grape water consumption of different treatment both present double-peak type in the whole growth period, new shoot growth period and fruit enlargement period are two peak of water consumption. The irrigation $6000 \mathrm{~m}^{3} / \mathrm{hm}^{2}$, nitrogen application $211.5 \mathrm{~kg} / \mathrm{hm}$ is most favorable for the growth of plants; Water and fertilizer combination value of the highest yield: $\mathrm{X} 1$-irrigation $=6345.5\left(\mathrm{~m}^{3} / \mathrm{hm}^{2}\right)$;X2-the amount of nitrogen $=240\left(\mathrm{~kg} / \mathrm{hm}^{2}\right)$; water and fertilizer combination value of the best quality:X1-irrigation $=5171.25\left(\mathrm{~m}^{3} / \mathrm{hm}^{2}\right) ; \mathrm{X} 2$-the amount of nitrogen $=211.5\left(\mathrm{~kg} / \mathrm{hm}^{2}\right)$; In condition that much water and less fertilizer, fertilizer use efficiency is the highest, reached $42.6 \%$, While fertilizer use efficiency of less water and much fertilizer treatment is the lowest, $23.45 \%$, From the economic point of view, treatment 3: irrigation $6000 \mathrm{~m}^{3} / \mathrm{hm}^{2}, \mathrm{~N} 193.5 \mathrm{~kg} / \mathrm{hm}^{2}$ is the optimal combination.

\section{Introduction}

China is an aried country, agricultural water consumption accounts for $80 \%$ of the total amount, irrigation water use efficiency is only $46 \%$, and has an enormous range with $70 \%$ in developed countries. Xinjiang is China's famous grape production base, but the region is also an arid area where it has serious water shortage, the shortage of water resources has become the main factor restricting the sustainable development of agriculture in the region, therefore, the development of water-saving irrigation technology has become one of the important ways to alleviate water shortages in the region.

Scholars from home and abroad have carried out extensive research on the coupling effect of water and fertilizer on the growth and yield of grape. C.Y. Zhao studied the grape coupling effect of water and fertilizer under drip irrigation, obtained the best ratio of water-fertilizer to yield, sugar content, VC and total acidity as target; Yambao's study showed that, the leaf water potential in fertilizer treatments under drought condition were lower than those in no fertilizer treatment, and decrease amplitude of the leaf water potential increases with the increase of fertilization level, leaf relative water content also showed the same trend; Thomas studied the effect of subsurface drip irrigation waternitrogen coupling on broccoli, 3 years experiments indicated that, nitrogen application significantly affect the utilization rate of nitrogen fertilizer, soil water content significantly affect the utilization rate of nitrogen fertilizer, reasonable water and fertilizer ratio is beneficial to improve water and fertilizer use efficiency; Dobermann A's study shows that, in the rice fertilizer application test, nitrogen, phosphorus, potassium, single factor applied, the rice yield was low , two factors applied, yield was higher, the three factor applied simultaneously yield was the highest ; Luo Shun studied the effects of water-fertilizer on growth and yield of wine grape in drip irrigation under film, obtained the best ratio of irrigation and fertilization to yield as target. Study on coupling of water and fertilizer on mature grape has acquired a large number of research results, but the study about coupling of water and fertilizer on the growth, yield, and quality effect of young grape are still few. Y.L.Li thinks, vegetative growth will have a direct impact on the development of reproductive organs, vegetative growth is poor, the plant will be short and thin, floral organ development will be not complete, fruit growth retardation, 
resulting in a low yield. The premise of grape high yield, stable yield is grape foliage growth, so study the young grape growth for guiding the practice of production and achieving high yield and quality is important. But for the effects of water-fertilizer coupling on young grape growth and yield and quality has not been reported. Through the observation and analysis of characteristics of different water and fertilizer treatment on the growth and development of young grape under drip irrigation, exploring the effect of water and fertilizer coupling on growth development and yield quality of young grape, seeking the best ratio and threshold region for young grape.

\section{Materials and methods}

Test situation

Experiments were carried out in Shihezi City in 2011-2012, The test area is located in the northern slope of the Tianshan Mountains, the southern margin of the Junggar basin, it is a typical inland arid area, altitude is $360 \mathrm{~m}$, annual precipitation is $100-200 \mathrm{~mm}$, annual evaporation capacity is close to $1500 \mathrm{~mm}$. Soil texture is sandy loam soils, average dry density is $1.30 \mathrm{~g} / \mathrm{cm} 3$ range for $0-60 \mathrm{~cm}$ soil horizon, field water capacity is $26 \%$. Frey was as the test material, the age is 4 years, the planting direction is the east-west, spacing is $1 \mathrm{~m}$, and row spacing is $3.5 \mathrm{~m}$. Drip irrigation system arrangement: laying a drip irrigation tape on both sides of the grape, respectively from the root $30 \mathrm{~cm}$ and $20 \mathrm{~cm}$. The dripper flow is $2.8 \mathrm{~L} / \mathrm{h}$, dripper spacing is $30 \mathrm{~cm}$. As shown in figure 1.
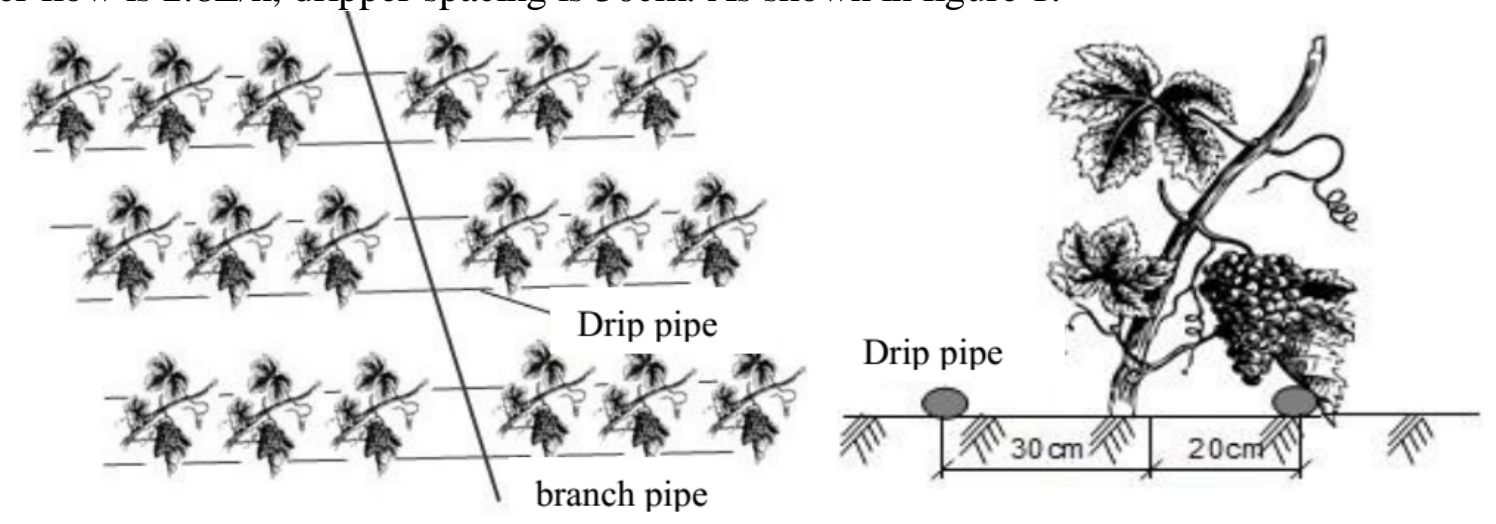

Figure 1. The test plot arrangement diagram of drip irrigation system

Experiment design

The test uses Binary quadratic orthogonal combination design, is two factors and three levels, a total of nine treatments, the specific design scheme in Table 1 and table 2 . Table 3 is irrigation rate during the whole growth period of grape in 2012, from April 25-October 30, 2012, a total of 9 times of irrigation.

Table. 1 The coding values of grape fertigation levels

\begin{tabular}{|c|c|c|c|c|}
\hline \multirow{2}{*}{ factor } & \multirow{2}{*}{$\begin{array}{c}\text { The spacing of } \\
\text { variables }\end{array}$} & \multicolumn{3}{|c|}{ level } \\
\hline & & -1 & 0 & 1 \\
\hline $\begin{array}{l}\text { Irrigation quantity } \\
\qquad\left(\mathrm{m}^{3} / \mathrm{hm}^{2}\right)\end{array}$ & 1125 & 3750 & 4875 & 6000 \\
\hline $\mathrm{N}\left(\mathrm{kg} / \mathrm{hm}^{2}\right)$ & 31.5 & 193.5 & 225 & 256.5 \\
\hline $\mathrm{P}\left(\mathrm{kghm}^{2}\right)$ & 27 & 160.5 & 187.5 & 213 \\
\hline $\mathrm{K}\left(\mathrm{kg} / \mathrm{hm}^{2}\right)$ & 40.5 & 237 & 277.5 & 316.5 \\
\hline
\end{tabular}


Table. 2 The design of grape Binary quadratic regression orthogonal combination

\begin{tabular}{|c|c|c|c|c|c|c|c|c|c|c|c|}
\hline \multirow{2}{*}{\multicolumn{2}{|c|}{ treatment }} & \multicolumn{3}{|c|}{ Code value } & \multicolumn{7}{|c|}{ The actual amount } \\
\hline & & \multicolumn{2}{|l|}{$\mathrm{X}_{1}$} & $\mathrm{X}_{2}$ & \multicolumn{2}{|c|}{$\begin{array}{c}\text { Irrigation } \\
\text { quantity }\end{array}$} & \multicolumn{2}{|l|}{$\mathrm{N}$} & \multicolumn{2}{|c|}{$\mathrm{P}$} & $\mathrm{K}$ \\
\hline \multicolumn{2}{|c|}{1} & 1 & \multicolumn{2}{|r|}{1} & \multicolumn{2}{|c|}{6000} & \multicolumn{2}{|c|}{256.5} & \multicolumn{2}{|c|}{213} & 316.5 \\
\hline \multicolumn{2}{|c|}{2} & 1 & \multicolumn{2}{|r|}{0} & \multicolumn{2}{|c|}{6000} & \multicolumn{2}{|c|}{225} & \multicolumn{2}{|c|}{187.5} & 277.5 \\
\hline \multicolumn{2}{|c|}{3} & 1 & \multicolumn{2}{|r|}{-1} & \multicolumn{2}{|c|}{6000} & \multicolumn{2}{|c|}{193.5} & \multicolumn{2}{|c|}{160.5} & 237 \\
\hline \multicolumn{2}{|c|}{4} & 0 & \multicolumn{2}{|r|}{1} & \multicolumn{2}{|c|}{4875} & \multicolumn{2}{|c|}{256.5} & \multicolumn{2}{|c|}{213} & 316.5 \\
\hline \multicolumn{2}{|c|}{5} & 0 & \multicolumn{2}{|r|}{0} & \multicolumn{2}{|c|}{4875} & \multicolumn{2}{|c|}{225} & 187 & & 277.5 \\
\hline & & 0 & & -1 & 4875 & & 193. & & 160 & & 237 \\
\hline & & -1 & & 1 & 3750 & & 256. & & 213 & & 1.41 \\
\hline & & -1 & & 0 & 3750 & & 225 & & 187 & & 0.71 \\
\hline & & -1 & & -1 & 3750 & & 193. & & 160 & & 1.05 \\
\hline & & Table & The & grape is & gation & time : & d irrig & ation $S$ & ale in & 2012 & \\
\hline $\begin{array}{l}\text { Time } \\
\text { Treat } \\
\text {-ment }\end{array}$ & $5-10$ & $5-25$ & $6-10$ & $6-22$ & $7-4$ & $7-18$ & $7-30$ & $8-15$ & $9-11$ & $\begin{array}{l}\text { Actual } \\
\text { irrigatio } \\
\mathrm{n}\end{array}$ & $\begin{array}{l}\text { Design } \\
\text { irrigation }\end{array}$ \\
\hline 1 & 547.5 & 609.0 & 684.0 & 714.0 & 729.0 & 697.5 & 700.5 & 622.5 & 750.0 & 6054.0 & 6000.0 \\
\hline 2 & 511.5 & 618.0 & 678.0 & 717.0 & 714.0 & 706.5 & 718.5 & 601.5 & 750.0 & 6015.0 & 6000.0 \\
\hline 3 & 537.0 & 627.0 & 691.5 & 720.0 & 723.0 & 702.0 & 712.5 & 618.0 & 750.0 & 6081.0 & 6000.0 \\
\hline 4 & 456.0 & 466.5 & 480.0 & 423.0 & 414.0 & 654.0 & 639.0 & 574.5 & 750.0 & 4857.0 & 4875.0 \\
\hline 5 & 457.5 & 459.0 & 474.0 & 414.0 & 429.0 & 652.5 & 625.5 & 607.5 & 750.0 & 4869.0 & 4875.0 \\
\hline 6 & 465.0 & 466.5 & 507.0 & 412.5 & 427.5 & 646.5 & 622.5 & 592.5 & 750.0 & 4890.0 & 4875.0 \\
\hline 7 & 327.0 & 382.5 & 354.0 & 384.0 & 354.0 & 505.5 & 490.5 & 307.5 & 750.0 & 3855.0 & 3750.0 \\
\hline 8 & 319.5 & 367.5 & 342.0 & 363.0 & 399.0 & 532.5 & 490.5 & 277.5 & 750.0 & 3841.5 & 3750.0 \\
\hline 9 & 336.0 & 346.5 & 330.0 & 378.0 & 414.0 & 504.0 & 489.0 & 268.5 & 750.0 & 3816.0 & 3750.0 \\
\hline
\end{tabular}

Determination indicators and methods

We selected grape aboveground biomass, yield and quality index to reflect the coupling effect of water and fertilizer on growth of young grape.

Determination of aboveground biomass : We Selected the 3 vines in each treatment, selected and marked a twig in upper, middle and lower part of each vines, determinated length and diameter of twig , leaf main vein length of marker twig, the average values of three duplicate is as the actual value. In fruit mature period, randomly selected 3 strings in upper, middle and lower part of each vines, weighed each string of ear fresh weight.

Determination of yield: Each treatment was randomly selected 10 strings of ear, weighed each string of ear fresh weight and got the average of each ear weight and the number of ear per treatment, the actual yield is string number multiplied by single string of ear weight in each treatment. Each ear picked 10 grapes, measured the diameter by Vernier caliper .

Determination of grape sugar content: Portable glucose meter. 


\section{Results}

Laws of water consumption

In the whole growth period, the water consumption of grape is different; it is mainly due to different growth period of climate characteristics and grape plant growth. Figure 2 shows the change of water consumption in soil profile at different growth stages. W1, W2, W3 treatment have the same irrigation quantity,W4, W5,W6 treatment have the same irrigation quantity, $\mathrm{W} 7, \mathrm{~W} 8, \mathrm{~W} 9$ treatment have the same irrigation quantity.
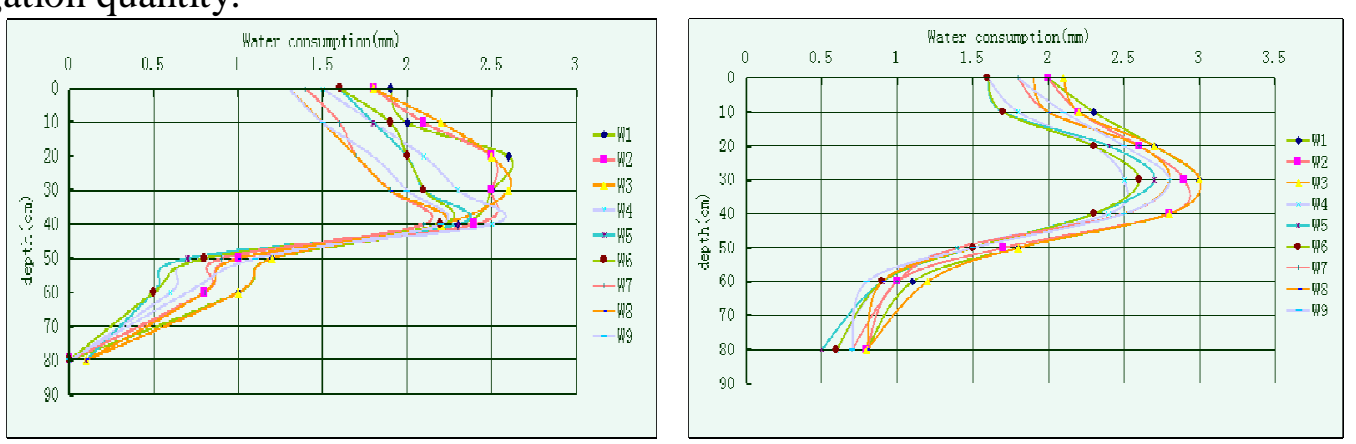

(a) water consumption of germination stage

(b) Water consumption of new shoot growth period
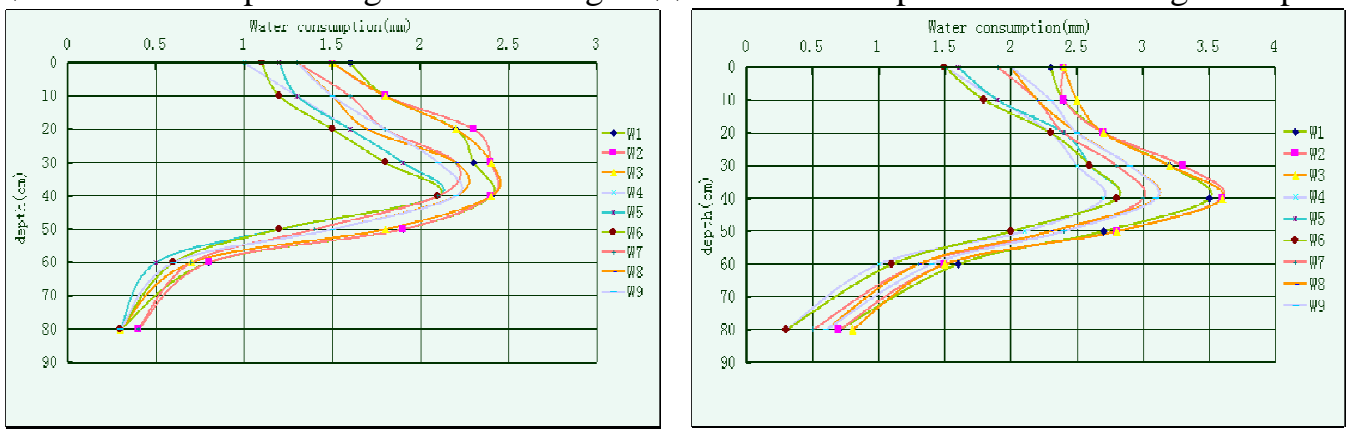

(c) Water consumption of flowering

(d) Water consumption of fruit enlargement period

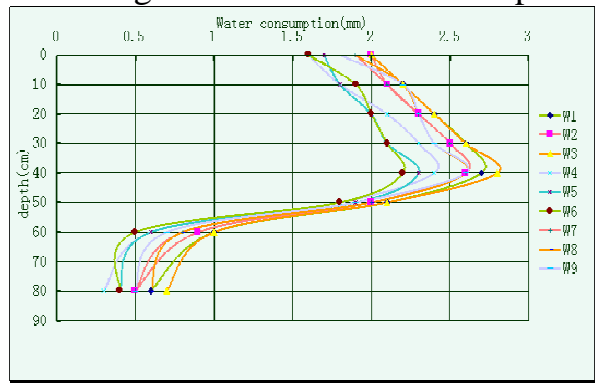

(e) Water consumption of fruit mature period

Fig. 2 The Changes of water consumption under different growth period

On the whole, as shown in Figure 2, the change trend of grape water consumption of each growth period is roughly the same. Water consumption intensity is greater with irrigation amount increasing under different water treatment, as W1、W2、W3 > W4、W5、W6>W7、W8、W9; This coincides with Zeng Chen's research conclusions. Under different fertilization conditions and with the same irrigation amount, more fertilizer, water consumption greater, as W1 $>\mathrm{W} 2>\mathrm{W} 3$; W4 $>\mathrm{W} 5>\mathrm{W} 6$; W7 $>$ W8 $>$ W9; This is because the soil moisture is a carrier which crops absorbed various nutrients, the more nutrient content; it needs to consume a lot of water to transmit. Overall, in the depth of $0-50 \mathrm{~cm}$, W1, W2, W3 treatment's grape water consumption is large, followed by W4、W5、W6 treatment, W7、 W8、W9 treatment's water consumption is the least. Below $50 \mathrm{~cm}$ layer, water consumption is no significant difference among different treatments, mainly because most of the water is absorbed by the root within above $50 \mathrm{~cm}$ soil; soil moisture is small in the deep soil.

Germination stage (4.25-5.12): Water consumption intensity is relatively low, the average of daily water consumption intensity is about $6 \mathrm{~mm}$, in the depth of $20-30 \mathrm{~cm}$, and water consumption is the 
largest. The water consumption has no significant difference between each treatment, this is mainly because the sprouting branches, leaf area, plant transpiration is weak in germination stage, it is smaller for water demand.

The shoot growth period (5.12-6.15): Compared with the germination stage's, water consumption intensity increased about $22 \%$ in the shoot growth period. In the depth of $30 \mathrm{~cm}$, water consumption is the largest. At this time, the twigs and leaves of the grape coming into the vigorous growth, all aspects of the grape physiological activities are speeding up, and it needs to consume a large amount of water, at the stage, the rapid increase in temperature and solar radiation, transpiration and evaporation of new leaves become strong.

Florescence (6.15-6.23): According to the grape management experience, too much water will cause the falling flowers and affect fruit setting rate, so we had a certain control for the field irrigation, resulted in grape water consumption intensity decreased than new shoot growth period.

Fruit development stage(6.23-8.2):At this stage, water consumption intensity reaches the maximum, the average daily water consumption intensity is about $10 \mathrm{~mm}$. Fruit grows rapidly and requires a lot of water ,grape transpiration and field evaporation intensity reach the maximum strength. Water consumption of the maximum value at a depth of about $40 \mathrm{~cm}$, compared with the florescence, the depth is down, it is mainly due to root system spread with the growth of the plant, the scope of root water uptake are expanding, the main grape root concentrated at the depth of $40 \mathrm{~cm}$.

Fruit mature stage (8.2-8.30): At this stage, water consumption still maintains a certain amount .The average of daily water consumption intensity is about $7 \mathrm{~mm}$. During this period, the main shoot extension growth began to stop gradually, and thickening growth continue to strong; The fruit come into the second period of growth, it is mainly that the sugar content increased rapidly, the acid content decreased. The temperature and the intensity of solar radiation began to gradually reduce.

The growth status of grape branches and leaves

The strength of grape branches growth is one of the important biological characteristics, The branch growth depends on tree nutrient reserves at the same time, the external moisture conditions is another important factor that affecting grape plant shoot growth. Figure 1 shows grapes changes of shoot length, diameter, and length of the main vein of leaves from the shoot growth period to fruit mature period under different water and fertilizer treatment.

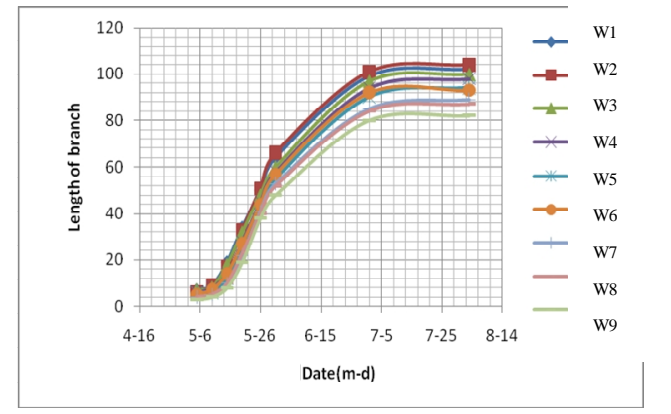

(a)

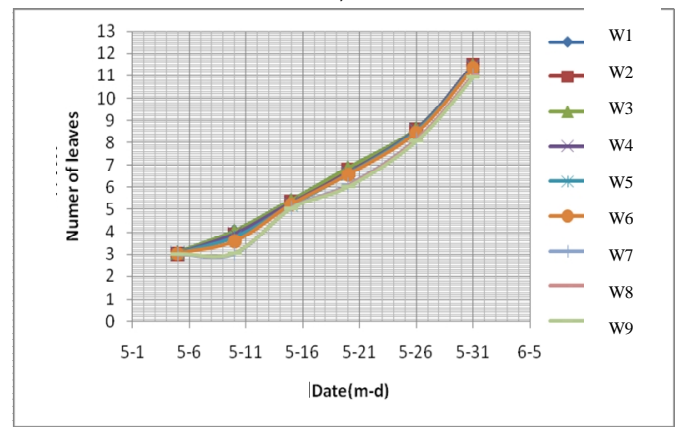

(c)

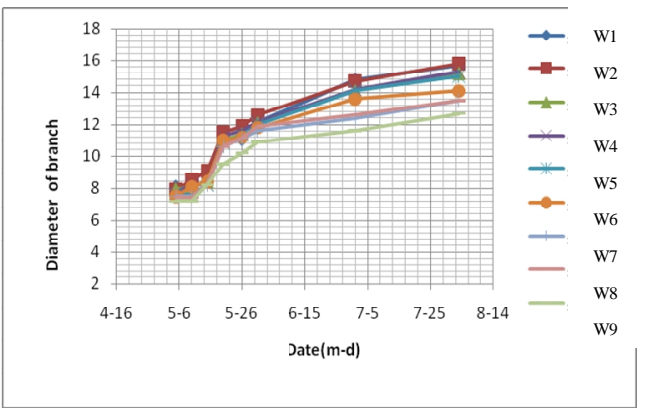

(b)

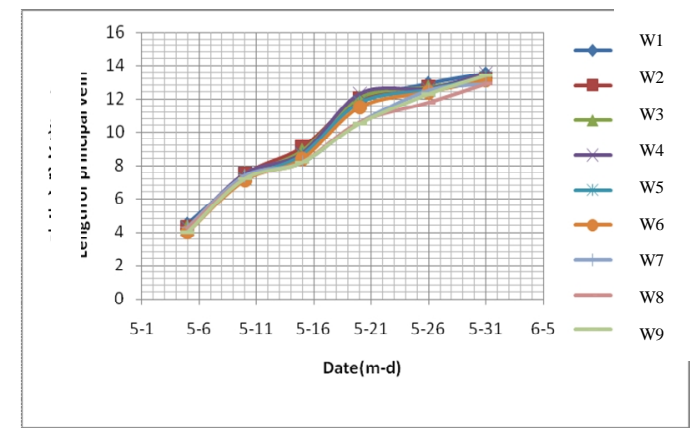

(d)

Fig.3 The process of leaf number, branch diameter, shoots length, and length of main vein under different treatment 
As shown in Figure 3 (a), in the whole growth period, grape shoot growth was shown a typical "S" curve, The first inflection point in May 20th that the new branches began to grow rapidly in shoot growth period, the second inflection point in June 30th that the growth began to slowly in fruit enlargement stage. Figure 3 (a) shows, irrigation quota directly affect the size of the grape branches growth, in a certain range, shoot length increases with the increase of irrigation quota, at germination stage, due to less bud branches, small leaves, weak plant transpiration, the requirement of water is small. The grape branches growth had no obvious difference under 3 different irrigation quota of water treatment, The branches length of the growth is concentrated in the shoot growing period, At this time, shoot growth of the treatment is the fastest that applied a large amount of irrigation and fertilization. During the fruit enlargement stage, branch growth is slow. The order of branch growth: W1, W2, W3 > W4, W5, W6>W7, W8, W9.

Figure 3 (b) shows the shoot diameter changes with time. In the germination stage, water demand is small for plant, so the treatment had no significant difference in the diameter of branches. From blossom and fruit period to the fruit enlargement period, the branches diameter: W1, W2, W3 >W4, W5, W6>W7, W8, W9, This is mainly because the branches thickening growth is more sensitive to moisture. Sato N, Mitehell P D and Silva $C$ believe that the change of the branches diameter reflects the relationship between transpiration rate and water level, and plant water status.

Figure 3 (c) shows the changes of leaf quantity with time. The number of leaf growth was mainly concentrated on the shoot growing period, there is no significant difference between the leaf numbers of each treatment, and overall, it shows an increase in exponential trend.

Figure 3 (d) shows the changes of leaf main vein length with time. Leaf main vein length growth was mainly concentrated on the shoot growing period; the mature leaf growth rate tends to slow. Leaf main vein length of each treatment was shown ' $S$ ' curve, The inflection point in May 10th that the early period of new shoot growth, leaf growth is vigorous, the second inflection point in May 20th that the later period of new shoot growth ,the leaf growth tends to slow. The treatment that applied minimum water of main vein length significantly less than other treatment under 3 different irrigation quota of water treatment.

From the above figure. 3 can be seen, branches growth, the number of leaves and main vein length are closely related with the amount of irrigation, and the relationship with the amount of fertilizer is not obvious. Synthesized grape leaves growing situation, W1 and W2 grape growing well, there is no obvious difference between W3, W4 and W5. Taking into account the vegetative growth is able to absorb moisture and mineral nutrients and accumulation of photosynthetic products and provide material and energy base for reproductive reproduction, to improve the yield and quality of grape, So that the irrigation $6000 \mathrm{~m}^{3} / \mathrm{hm}^{2}$, nitrogen application $211.5 \mathrm{~kg} / \mathrm{hm}^{2}$ is most favorable for the growth of plants.

The yield and quality of grape

In August 23, 2012, the size and quality of grape cluster, the weight and diameter of fruit grain were measured; the measurement results are shown in the following table.

Table 4 Ear and berry under different treatment

\begin{tabular}{|c|c|c|c|c|c|c|c|c|c|c|}
\hline $\begin{array}{l}\text { Treat } \\
\text { ment }\end{array}$ & $\begin{array}{l}\text { irrigation } \\
\text { scale }\end{array}$ & $\begin{array}{l}\text { Nitrogen } \\
\text { rate }\end{array}$ & $\begin{array}{l}\text { Ear length } \\
\quad(\mathrm{cm})\end{array}$ & $\begin{array}{c}\text { Ear } \\
\text { width } \\
(\mathrm{mm})\end{array}$ & $\begin{array}{c}\text { Ear } \\
\text { weight } \\
(\mathrm{g})\end{array}$ & $\begin{array}{c}\text { Berry } \\
\text { longitudinal } \\
\text { diameter }(\mathrm{mm})\end{array}$ & $\begin{array}{c}\text { Berry } \\
\text { transverse } \\
\text { diameter } \\
(\mathrm{mm}) \\
\end{array}$ & $\begin{array}{l}\text { Single } \\
\text { fruit } \\
\text { weight } \\
(\mathrm{g}) \\
\end{array}$ & $\begin{array}{l}\text { Yield } \\
\text { per ha }\end{array}$ & $\begin{array}{c}\text { Sugar } \\
\text { content } \\
\%\end{array}$ \\
\hline 1 & 1 & 1 & $13.5 b$ & $11.8 \mathrm{a}$ & $379.6 a$ & $1.7 \mathrm{bc}$ & $1.7 \mathrm{a}$ & $3.1 \mathrm{a}$ & $7140 \mathrm{~d}$ & $19 \mathrm{~cd}$ \\
\hline 2 & 1 & 0 & $13 b$ & $11.3 \mathrm{~b}$ & $366.7 b$ & $1.8 \mathrm{ab}$ & $1.6 \mathrm{ab}$ & $2.9 \mathrm{bc}$ & $7455 \mathrm{c}$ & $18.5 \mathrm{fg}$ \\
\hline 3 & 1 & -1 & $15 \mathrm{a}$ & $11.8 \mathrm{a}$ & $357.2 \mathrm{c}$ & $1.7 \mathrm{bc}$ & $1.5 \mathrm{bc}$ & $2.75 \mathrm{de}$ & $8250 a$ & $18.1 \mathrm{~g}$ \\
\hline 4 & 0 & 1 & $10 \mathrm{c}$ & $10.5 \mathrm{~d}$ & $339.4 d$ & $1.6 b c$ & $1.5 \mathrm{bc}$ & $2.5 \mathrm{hi}$ & $7530 \mathrm{bc}$ & $18.9 \mathrm{de}$ \\
\hline 5 & 0 & 0 & $15.8 \mathrm{a}$ & $10.5 \mathrm{~d}$ & $351.5 \mathrm{c}$ & $1.7 b c$ & $1.6 \mathrm{ab}$ & $2.8 \mathrm{cde}$ & $6885 f$ & $18.8 \mathrm{def}$ \\
\hline 6 & 0 & -1 & $13.5 b$ & $9.8 \mathrm{e}$ & $317.8 \mathrm{e}$ & $1.6 \mathrm{~cd}$ & $1.5 \mathrm{bc}$ & $2.58 \mathrm{gh}$ & $6795 \mathrm{ef}$ & $18.2 \mathrm{fg}$ \\
\hline 7 & -1 & 1 & $10.8 \mathrm{c}$ & $10.8 \mathrm{c}$ & $238.7 f$ & $1.6 \mathrm{~cd}$ & $1.5 b c$ & $2.5 \mathrm{ij}$ & $6015 \mathrm{ij}$ & $20.5 a$ \\
\hline 8 & -1 & 0 & $10.25 c$ & $9.75 \mathrm{e}$ & $237.7 f$ & $1.8 \mathrm{ab}$ & $1.7 \mathrm{a}$ & $2.43 \mathrm{ijk}$ & $6075 \mathrm{ghi}$ & $19.7 \mathrm{~b}$ \\
\hline 9 & -1 & -1 & $14.8 \mathrm{a}$ & $10.8 \mathrm{c}$ & $216 \mathrm{~g}$ & $1.7 \mathrm{bc}$ & $1.6 \mathrm{ab}$ & $2.7 \mathrm{ef}$ & $6000 \mathrm{jk}$ & $17.6 \mathrm{f}$ \\
\hline
\end{tabular}

We analyzed the significance of above data by using SPSS software, from the table we can see, on the whole, under water deficit conditions, no matter what kind of fertilizer level, grape yield, ear weight, grain weight were obviously restricted. This shows external factors that the restriction of grape growth 
is mainly to water, this may be due to irrigation quota is smaller, the crop growth stage of water allocation less, caused soil lack of water and plants drought, reduced leaf photosynthesis, affected the flower bud differentiation and reduced ear number, in addition, affected the process of nutrient synthesis, transport, accumulation and grain formation.

From the above table can be seen, on different soil water conditions that fertilization can improve crop yields, this is likely because soil water potential is low, fertilization increases stomatal resistance, reduces the transpiration intensity, but the higher soil water potential, fertilization reduces the stomatal resistance, increases the transpiration intensity ; the transpiration of fertilizer treatment increased , facilitates

The uptake of water and nutrients and the formation of high yield; when the water supply is shortage, the transpiration of fertilizer treatment reduced, there is conducive to water conservation and adaptation to drought stress.

The relationship between fertigation and sugar content is significant ,in a certain range, the less irrigation, the more fertilization, more sugar accumulation, this is mainly due to fertilizer can improve the moisture of root system, increase the root water potential and increase evapotranspiration, form more photosynthetic products, so as to improve fruit total soluble sugar; If irrigation is more, it will strengthen the trees vegetative growth, promote the conversion of sugar into the amino acid and protein, reduce sugar accumulation in fruit. Fruit vertical and horizontal diameter had no significant relationship with irrigation and fertilization, which may be related to the grape varieties.

According to the quadratic regression orthogonal combination of design principles, the grape yield and quality (sugar) as the objective function (the dependent variable), the regression mathematical model to calculate the dependent variable factors and the coding value.

$$
\begin{aligned}
& \text { Yield: } Y^{\prime}=402.11+27.83 X_{1}+12.33 X_{2}+8.33 X_{1} X_{2}-20.2 X_{1}^{2}-20.7 X_{2}^{2} \\
& \text { Quality: } Y^{\prime}=18.89+0.23 X_{1}+0.72 X_{2}-0.17 X_{1} X_{2}-0.97 X_{12}+0.77 X_{22}
\end{aligned}
$$

Formula (1) (2) in X1, X2 representing the amount of irrigation, fertilization of two factors.

In the application process of mathematical model of grape yield, we can obtain the best value of water and fertilizer combination when the yield and quality is highest through the model. According to the grape yield regression equation (1) (2) were seeking partial derivative, get the following equation:

$$
\begin{array}{ll}
\frac{\mathrm{d} y^{\prime}}{d x_{1}}=27.83+8.33 x_{2}-40.4 x_{1} & \frac{d y^{\prime}}{d x_{1}}=0.23-0.17 x_{2}-1.94 x_{1} \\
\frac{d y^{\prime}}{d x_{2}}=12.33+8.33 x_{1}-41.4 x_{2} & \frac{d y^{\prime}}{d x_{2}}=0.72-0.17 x_{1}+1.54 x_{2}
\end{array}
$$

Solving the above equations, we can get the code values of the variables:

$$
\begin{array}{ll}
X_{1}{ }^{\prime}=0.783 & X_{1}{ }^{\prime}=0.158 \\
X_{2}{ }^{\prime}=0.455 & X_{2}{ }^{\prime}=-0.45
\end{array}
$$

According to $\left(\mathrm{X}_{\mathrm{j}}-\mathrm{X}_{0 \mathrm{j}}\right) / \Delta_{\mathrm{j}}=\mathrm{X}_{\mathrm{j}}{ }^{\prime}$, The actual value of the factor levels can be obtained by coded values substitution, The range of this experiment, water and fertilizer combination value of the highes $\mathrm{t}$ yield: $\mathrm{X}_{1}$-irrigation $=6345.5\left(\mathrm{~m}^{3} / \mathrm{hm}^{2}\right) ; \mathrm{X}_{2}$-the amount of nitrogen $=240\left(\mathrm{~kg} / \mathrm{hm}^{2}\right) ;$ water and fertilizer c ombination value of the best quality: $X_{1}$-irrigation $=5171.25\left(\mathrm{~m}^{3} / \mathrm{hm}^{2}\right) ; X_{2}$-the amount of nitrogen=211. $5\left(\mathrm{~kg} / \mathrm{hm}^{2}\right)$;

Analysis of water and fertilizer using efficiency and economic benefits

Water use efficiency (WUE) refers to the assimilation of plant consuming per unit water, reflects the energy conversion efficiency of the production process of plant, it is also one of the comprehensive index for evaluating growth suitability degree of plant water conditions. This test uses the ratio of 
irrigation to yield to express. Fertilizer partial productivity means the ratio of yield and fertilizer amount after fertilization, it reflects the marginal effects caused by crop uptake of fertilizer .Table 5 lists the different treatment of grape water use efficiency and fertilizer use efficiency. Table 6 lists the grape economic benefit of different water and fertilizer combination.

Table 5 Water and fertilizer use efficiency under different treatment

\begin{tabular}{cccccc}
\hline Treatment & $\begin{array}{c}\text { Irrigation } \\
\text { quota }\end{array}$ & Nitrogen rate & Yield & (WUE) & (FUE) \\
\hline 1 & 6054 & 256.5 & 7140 & $1.179 \mathrm{dE}$ & $27.836 \mathrm{deCD}$ \\
2 & 6015 & 225 & 7455 & $1.239 \mathrm{dDE}$ & $33.133 \mathrm{bcBC}$ \\
3 & 6081 & 193.5 & 8250 & $1.357 \mathrm{cCD}$ & $42.636 \mathrm{aA}$ \\
4 & 4857 & 256.5 & 7530 & $1.550 \mathrm{aAB}$ & $29.357 \mathrm{cdCD}$ \\
5 & 4869 & 225 & 6885 & $1.414 \mathrm{bcBC}$ & $30.600 \mathrm{cdBCD}$ \\
6 & 4890 & 193.5 & 6795 & $1.390 \mathrm{cC}$ & $35.116 \mathrm{bB}$ \\
7 & 3855 & 256.5 & 6015 & $1.560 \mathrm{aAB}$ & $23.450 \mathrm{eDEF}$ \\
8 & 3841.5 & 225 & 6075 & $1.581 \mathrm{aA}$ & $27.000 \mathrm{deDE}$ \\
9 & 3816 & 193.5 & 6000 & $1.572 \mathrm{aA}$ & $31.008 \mathrm{bcdBCD}$ \\
\hline
\end{tabular}

Under different fertilizer treatments, the yield increased with increasing irrigation amount. This shows that in the range of the experiment, water is the main factor that restricts the production. Compared water use efficiency under different fertilizer combinations, we can see, water use efficiency gradually decreased with the increase of irrigation water, which is consistent with the general law. Water use efficiency is higher under the treatment of much water and less fertilizer and the treatment of appropriate water and much fertilizer, this is because fertilization improved plant osmotic adjustment ability and inhibited transpiration. Compared fertilization use efficiency under different fertilizer combination, we can see, in the same amount of irrigation, with the increase of the amount of fertilizer, fertilizer use efficiency correspondingly reduced 5\%-10\%, which is consistent with the general law. In condition that much water and less fertilizer, fertilizer use efficiency is the highest, reached $42.6 \%$, While fertilizer use efficiency of less water and much fertilizer treatment is the lowest, $23.45 \%$, this is because when the soil moisture content is deficient, the moisture directly inhibit the normal growth and development, weakened plant photosynthesis, reduced dry matter, resulted in the low fertilizer utilization rate.

Table 6 Economic benefits under different treatment

\begin{tabular}{cccccccc}
\hline $\begin{array}{c}\text { Treatment } \\
\mathrm{s}\end{array}$ & Yield & output value & $\begin{array}{c}\text { Fertilizer } \\
\text { cost }\end{array}$ & Water cost & Total input & profit & Input/output \\
\hline 1 & 7140 & 64260 & 2718.9 & 2118.9 & 4837.8 & 59422.2 & 13.27 \\
2 & 7455 & 67095 & 2385 & 2105.25 & 4490.25 & 62604.75 & 14.94 \\
3 & 8250 & 74250 & 2051.1 & 2128.35 & 4179.45 & 70070.55 & 17.79 \\
4 & 7530 & 67770 & 2718.9 & 1699.95 & 4418.85 & 63351.15 & 15.35 \\
5 & 6885 & 61965 & 2385 & 1704.15 & 4089.15 & 57875.85 & 15.17 \\
6 & 6795 & 61155 & 2051.1 & 1711.5 & 3762.6 & 57392.4 & 16.26 \\
7 & 6015 & 54135 & 2718.9 & 1349.25 & 4068.15 & 50066.85 & 13.30 \\
8 & 6075 & 54675 & 2385 & 1344.525 & 3729.525 & 50945.475 & 14.65 \\
9 & 6000 & 54000 & 2051.1 & 1335.6 & 3386.7 & 50613.3 & 15.95 \\
\hline
\end{tabular}

The pros and cons of effect of one combination of water and fertilizer is not only measured by yield, various factors should be considered, and comparison of different economic benefits, finally 
determined the treatment of good index is the best fertigation combination. Compared different treatment of the output-input ratio, the output-input ratio is the highest under the treatment of much water and less fertilizer, while the less water and much fertilizer treatment is the lowest, this is because the economic benefits depends on the input and output, in the larger amount of fertilizer, the amount of water should be increased, to achieve the effect of promoting fertilizer, play the role of fertilizer. From the economic point of view, treatment 3: irrigation $6000 \mathrm{~m}^{3} / \mathrm{hm}^{2}, \mathrm{~N} 193.5 \mathrm{~kg} / \mathrm{hm}^{2}$ are the optimal combination.

Under different fertilizer treatments, the yield increased with increasing irrigation amount. This shows that in the range of the experiment, water is the main factor that restricts the production. Compared water use efficiency under different fertilizer combinations, we can see, water use efficiency gradually decreased with the increase of irrigation water, which is consistent with the general law. Water use efficiency is higher under the treatment of much water and less fertilizer and the treatment of appropriate water and much fertilizer, this is because fertilization improved plant osmotic adjustment ability and inhibited transpiration. Compared fertilization use efficiency under different fertilizer combination, we can see, in the same amount of irrigation, with the increase of the amount of fertilizer, fertilizer use efficiency correspondingly reduced 5\%-10\%, which is consistent with the general law. In condition that much water and less fertilizer, fertilizer use efficiency is the highest, reached $42.6 \%$, While fertilizer use efficiency of less water and much fertilizer treatment is the lowest, $23.45 \%$, this is because when the soil moisture content is deficient, the moisture directly inhibit the normal growth and development, weakened plant photosynthesis, reduced dry matter, resulted in the low fertilizer utilization rate.

\section{Discussion}

In the whole growth period, the water consumption of grape is different, it presents: water consumption in germination stage is low, water consumption in the shoot growth period is relatively large, water consumption in flower period is relatively low, in the whole growing stage, water consumption in fruit enlargement period is the largest. This coincides with ZengChen's research conclusions.

Water and fertilizer are two important factors to affect the yield and quality of grape, water deficit will reduce the grapes yield, fertilizer deficit not only reduced yield, and limited the use of grapes on the water. Therefore, to determine the reasonable fertilization must be combined with water. Lahirri, A.N found, fertilization can promote the ability of crop root growth and uptaking and transporting soil moisture under drought stress, expand the space of absorbing soil nutrient and water, improve the efficiency of utilization and water transpiration. Shen Rongkai studied, under different farmland water status and the same amount of fertilizer, the yield is not the same, generally speaking, efficiency increased with the increase of irrigation water. This experiment measures the grapes growth index under different water and fertilizer combinations, there were significant differences among different treatments, irrigation $6000 \mathrm{~m}^{3} / \mathrm{hm}^{2}, \mathrm{~N} 256.5 \mathrm{~kg} / \mathrm{hm}^{2}$, its growth index is the optimal in all treatment, it shows that branch length, stem diameter, leaf number, leaf main vein length showed better growth under sufficient water condition, and in a certain range, the more fertilizer, plant growth is more 
vigorous, this is coincides with Shen Rongkai 's research conclusions.

Reducing the amount of irrigation and fertilizer can improve the quality of grape, but the yield and economic benefits will be reduced; Increasing the amount of irrigation properly can improve the yield of grapes, but not significantly reduce water use efficiency ${ }^{[21]}$; Therefore, under the condition of high

yield and high water use efficiency, we can considered the appropriate choice of the treatment of much water and less fertilizer and the treatment of appropriate water and much fertilizer. From the results of this study, in the Shihezi area, water is the main factor influencing the yield and economic benefit. In the lower fertilization conditions, increasing irrigation amount to obtain high yield, and also improve fertilizer use efficiency; On the other hand, from the perspective of saving water, increasing the amount of fertilizer and reducing irrigation water can effectively improve water use efficiency and fruit quality, But in the larger amount of fertilizer, we should increase the amount of irrigation to play the role of fertilizer in water, but also we must take into account the economic benefits of grape. J.J Baselge Yrisarry and Tang Y X found, in general, the fertilization effect is increased with the increase of moisture content, when the soil moisture content is deficient, the moisture directly inhibit the normal growth and development, weakened plant photosynthesis, reduced dry matter, resulted in the low fertilizer utilization rate. Different soil environment is for different water and fertilizer ratio, generally, low fertilizer and high water is suitable for soil fertility was higher in plots, at this time, we can appropriately reduce the amount of fertilizer and increase irrigation water amount. If the irrigation cost is higher, we can consider the combination of appropriate water and fertilizer, also we can get high yield through low investment. synthesized all the indexes, It was found that the treatment of appropriate water and fertilizer can greatly improve the grape yield and water use efficiency, and grapes grow well, while the maximum economic benefit.

\section{Conclusion}

Irrigation quota is $6000 \mathrm{~m}^{3} / \mathrm{hm}^{2}$, nitrogen $256.5 \mathrm{~kg} / \mathrm{hm}^{2}$, vegetative growth of grape is vigorous; by the mathematical model, we obtained the water and fertilizer combination value of the highest yield: $X_{1}$-irrigation $=6345.5\left(\mathrm{~m}^{3} / \mathrm{hm}^{2}\right) ; \mathrm{X}_{2}$-the amount of nitrogen $=240\left(\mathrm{~kg} / \mathrm{hm}^{2}\right) ;$ water and fertilizer combination value of the best quality: $\mathrm{X}_{1}$-irrigation $=5171.25\left(\mathrm{~m}^{3} / \mathrm{hm}^{2}\right) ; \mathrm{X}_{2}$-the amount of nitrogen $=211.5\left(\mathrm{~kg} / \mathrm{hm}^{2}\right)$.

Irrigation quota is $6000 \mathrm{~m}^{3} / \mathrm{hm}^{2}$, nitrogen $193.5 \mathrm{~kg} / \mathrm{hm}^{2}$ and irrigation quota is $4875 \mathrm{~m}^{3} / \mathrm{hm}^{2}$, nitrogen $256.5 \mathrm{~kg} / \mathrm{hm}^{2}$, have higher water use efficiency; In condition that much water and less fertilizer, fertilizer use efficiency is the highest, While fertilizer use efficiency of less water and much fertilizer treatment is the lowest, from the economic point of view, treatment 3: irrigation $6000 \mathrm{~m}^{3} / \mathrm{hm}^{2}, \mathrm{~N}$ $193.5 \mathrm{~kg} / \mathrm{hm}^{2}$ is the optimal combination.

Considering the subsequent young grape yield, in young period, grape need to increase the amount of water and fertilizer to ensure the growth of branches, therefore, we can consider the treatment of irrigation $6000 \mathrm{~m}^{3} / \mathrm{hm}^{2}, \mathrm{~N} 225 \mathrm{~kg} / \mathrm{hm}^{2}$. 


\section{Acknowledgments}

We are grateful to Dr. Xinlin He of the College of Water Conservancy \& Architectural Engineering Shihezi University, for valuable advice throughout this study. We additionally acknowledge H.G. Liu and G. Yang for technical assistance. Finally, this work was financially supported by the National Natural Science fund project (U1203282) (51269026).

\section{References}

[1] Zhang, Y.Z. Shen, J.M. WangJ.Z. (2007)Researching actually and development of surface irrigation technique. Agro-Environment \& Development, 1:20 26.

[2] Singh, K.P .Kumar V. (1981) Water use and water use efficiency of wheat and barley in relation to seeding dates, levels of irrigation and nitrogen fertilization. Agricultural Water Management ,3 (4): $305 \sim 316$.

[3] Hebbar, S.S, Ramachandrappa, B.K, Nanjappa, H .V. (2004) Studies on NPK drip fertigation in field grown tomato (Lycopersicon esculentum Mill) . European Journal of Agronomy, 21 (1) : $117 \sim 127$.

[4] Thomas, L. Thompsona, Thomas, A. (2000) Nitrogen and Water Interactions in Subsurface Drip Irrigated Cauliflower. Soil Science Society of America Journal, 64: 412 418 .

[5] Huang,M.B. Dang, T.H. Gallieh and J, etal. (2003) Effect of increased fertilizer applications to wheat crop on soil water depletion in the Loess Plateau,China. Agricultural Water Management, 58:267 278.

[6] Obreza, T.A. Rouse,R.E.(1993)Fertilizer effects on early growth and yield of "Hamlin"orange trees. HortScience, 28(2):111 114.

[7] Zhao C.Y. (2005) Reponse and interaction for water and fertilizer of grape with drip irrigation. XinJiang: Xin Jiang Agricultural University.

[8] Yambao,E.B. and Toole,J.C. (1984) Effects of nitrogen and root medium water Potential on Growth nitrogen uptake and osmotic adjustment of rice.Physiol. Plant, 60:507 515.

[9] Dobermann,A, Cassman,K.G, Mamaril, C.P, etal. (1998)Management of Phosphorus, Potassium, and sulphur in intensive, irrigated lowland rice.Field Crops Research, 6:113-138.

[10] Luo, S. (2011) The Influence of Fertilizer and Underfilm Drip Irrigation to Growth and Production to Cuktivation of Grapes Making Wine. YangLing: North West Agriculture and Forestry University.

[11] Li, Y.L. Zhang, A.M. (2012) the dialectical relationship of vegetative growth and reproductive growth of plant.Chinese Horticulture Abstracts, 2:36-37.

[12] Sato,N. Hasegaw, A.K. (1995)A computer controlled irrigation system for muskmelon using diameter sensor. Acta. Horticulture, 399: 161 163 .

[13] Mitehell, P.D, vande, E.B. Jerie, P.H, etal. (1989)Response of 'barlett' pear to withholding irrgation,regulated deficit irrjgation and tree spacing. J Amer. Soc. Hort. Sci, 114: 15.

[14] Silva, contreras D. Selles, Von schouwen G. Ferreyra Espada R. (2012)Varition of water potential and trunk diameter answer as sensitivity to the water avaivability in table grapes. Chilean Journal of argicultural research. 72(4):459 469 .

[15] Zeng, C. (2010) The Growth Characteristics and High Water Use Efficient on Mature Grape under Extremely Drought Region. YangLing: Graduate University of Chinese Academy of Sciences.

[16] Lahirri, A.N. Turner,N.C. And Kramer, P,J . (1980)Interaction of water stress and mineral nutrition on growth and yield. Adaptation of Plants to water and high temperature stress. New York: Wiley Inter Science, $341 \sim 342$.

[17] M.Henry,H.Stevens, Rebecca shirk. (2006)Water and fertilizer have opposite effects on plant species richness in a mesic early successional habitat. Plant Ecology, 183:27 34. 
[18] Hu, H.Y, Ning, T.Y, Li, Z.J, etal.(2013)Coupling effects of urea types and subsoiling on nitrogen $\sim$ water use and yield of different varieties of maize in northern China . Field crops research, 142:85 94.

[19] LV,J.L. WU, R.G. FAN, Y.Q, etal. (2012)Relationship between Fertilization and Drought Resistance of Crop under Drought Condition. Acta Agriculture Jiangxi,24( 2) : $6 \sim 10$.

[20] Sheng, R .K, Wang, K. (2001)Field Test and Study on Yield, Water Use and N Uptake Under Varied Irrigation and Fertilizer in Crops. The Chinese Society of Agricultural Engineering, 17 (5): $40 \sim 43$.

[21] Luo, Y. H. (2012)Growth Characteristic and Irrigation System Research on Protected Grapes under Drip Irrigation. LanZhou: Gansu Agricultural University.

[22] Baselge Yrisarry, J.J. Prieto Losada, M.H and del Rincon,A.R. (1993) Response of processing tomato to three different levels of water and nitrogen applications. Acta Horticulture, 335: 149 153.

[23] Tang, Y .X, Meng, C. X, Jia, S .L, et al. (1996)Different responses of wheat to water and fertilizer and technique of fertilizer application to wheat with water $\sim$ saving irrigation in winter. Agric. Res. Arid Areas, 14: 36 40. 